\title{
Factors affecting prospective mathematics teachers' beliefs about geometric habits of mind
}

\author{
Buket Özüm Bülbül \\ Manisa Celal Bayar University, Turkey
}

\begin{abstract}
This study examined the effect of affective factors, the gender variable, grade level and academic achievement on prospective teachers' (PTs) beliefs about geometric habits of mind. For this purpose, The Belief Scale for geometric habits of mind, Geometry Self-efficacy Scale, Geometry Attitude Scale and a Demographic Characteristics Form were applied to 264 PTs. The data were analyzed using the correlational survey technique. As a result of the study, a significant positive relationship was found between the PTs' self-efficacy regarding geometry and their academic achievements, and their beliefs about geometric habits of mind, Additionally a negative, moderate and significant relationship was found between the attitudes of the PTs towards geometry and their beliefs about geometric habits of mind. Finally, no significant difference was found between the scores of the PTs regarding geometric habits of mind and their gender.
\end{abstract}

Keywords: Attitude; Beliefs; Geometric habits of mind; Geometry; Self-efficacy

Article History: Submitted 22 November 2020; Revised 12 March 2021; Published online 7 April 2021

\section{Introduction}

Geometry teaching includes the teaching of a number of skills, including the development of reasoning skills, enabling visualization of the concepts and relationship in geometric figures, overcoming problems encountered in daily life, and the knowledge of other subfields of mathematics (Clements, 2003; Gonzalez \& Herbst, 2006; Herbst, 2006). In addition to these, the main building blocks of teaching mathematics in general, and geometry, in particular are problemsolving skills (Đokić, 2018; National Council of Teachers of Mathematics, 2000). Problem-solving means that individuals are able to overcome the problems they face, and can find solutions if faced with a similar situation again (Schoenfeld, 1992). Helping students learn how to problem-solve thus makes their knowledge of mathematics and geometry more permanent (Clements, 2003; Herbst, 2006; Schoenfeld, 1992). Students tend to use previously acquired habits while trying to overcome the problems they are encountering. Choosing what will work from their pool of habits and using the selected habit appropriately play an important role in overcoming any problem

\section{Address of Corresponding Author}

Buket Özüm Bülbül, PhD, Manisa Celal Bayar University, Faculty of Education, Department of Science and Mathematics Education, Demirci, 45190, Manisa, Turkey.

\footnotetext{
$\triangle$ buket.bulbul@cbu.edu.tr

0000-0001-9610-7053
}

How to cite: Bülbül, B. Ö. (2021). Factors affecting prospective mathematics teachers' beliefs about geometric habits of mind. Journal of Pedagogical Research, 5(2), 36-48. http:/ /dx.doi.org/10.33902/JPR.2021068370 
faced. These habits, known as "habits of mind" in the literature, are the modes of thinking that come into play when it is not known how to solve a problem; they offer a range of potential choices to an individual (Costa \& Kallick, 2009). The literature divides habits of mind into "general habits of mind" and "domain-specific habits of mind" (Cuoco et al., 1996; Lim \& Selden, 2009). Lim and Selden (2009) exemplified the general habits of mind as being "pattern sniffing," "experimenting", "formulating", "tinkering," "inventing", "visualizing", and "conjecturing". Domain-specific habits of mind are defined as "engineering habits of mind", "scientific habits of mind", "calculating habits of mind", "mathematical habits of mind", "algebraic habits of mind", "probabilistic habits of mind" and "geometric habits of mind". Since this study is concerned with geometry, the focus here is on beliefs about "geometric habits of mind" (GHoM) and the factors which influence them.

\subsection{Cognitive and Affective Dimension of Geometric Habits of Minds}

GHoM are generative ways of thinking that support learning and teaching geometry (Driscoll et al., 2007). Mathematics students tend to use GHoM when they encounter a geometry problem. For example, when asked to find the area of given a triangle or square, their main tendency is to immediately write in the angles or draw parallels and thus seek a solution. In the few studies on GHoM in the literature, various indicators of GHoM have been defined. Goldenberg (1996) classified the GHoM that should be included in the curriculum under the name of "Connected Geometry" as follows: (a) the inclination to visualize when interpreting diagrams; (b) to describe formally and informally; (c) to translate between visually and verbally presented information; (d) to tinker; (e) to look for invariants; (f) to mix experiments with deductions; (g) to build systematic explanation and proof; (h) to construct and reason about algorithms; and (i) to reason by continuity. Similarly, Cuoco et al. (1996) described GHoM as (a) thinking about reasoning by continuity, (b) seeking geometric invariants, (c) looking at extreme cases and passing to the limit, (d) dynamically changing systems, (e) continuous deformations, and (f) continuous functions (p.685). Problem-solving and the definitions of GHoM are intertwined (National Council of Teachers of Mathematics, 2000). In other words, students' problem-solving skills and their tendency to use GHoM are influenced by each other (see in Figure 1).

Figure 1

Relationship between problem-solving and GHoM

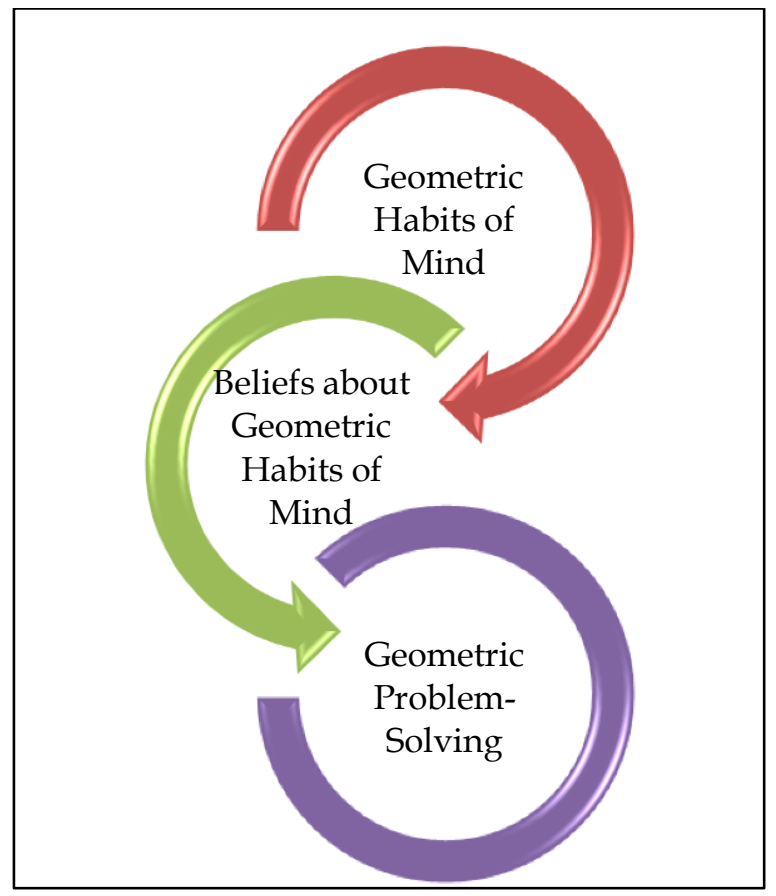


Habits of mind in mathematics in general, and in geometry, in particular, refer to the ways in which mathematics students approach a problem and think "like a mathematician" (Jacobbe \& Millman, 2009; Matsuura et al., 2013). Students' successes in problem-solving affect their GHoM and their beliefs about these habits (Driscoll et al., 2007; Driscoll et al., 2008; Gordon, 2011; Lai \& Donsing, 2018). Therefore, as seen in Figure 1, having positive beliefs about GHoM increases both students' problem-solving success and their reliance on GHoM (Bülbül \& Güven, 2019; Bülbül \& Güven, 2020; Costa \& Kallick, 2009; Erşen et al., 2018; Hanson \& Lucas, 2020). If students' beliefs about GHoM can be determined and learning environments be designed with regard to those beliefs, students' success in problem-solving and ability to engage in GHoM will increase.

Beliefs about GHoM reflect the affective dimension of the students' attitudes and behaviors when they encounter a geometry problem that they do not know the direct solution to. The affective dimension of GHoM includes the feelings and beliefs that students have while solving a geometry problem. When the studies on GHoM in the literature are examined, it can be seen that research has generally focused on the cognitive dimension of these habits (Driscoll et al., 2007; Driscoll et al., 2008; Goldenberg, 1996; Cuoco et al., 1996; Yavuzsoy-Köse \& Tanışl1, 2014). Costa and Kallick (2009), which is a good example of a study focusing on the affective dimension of habits of mind, classified them as: "thinking flexibly, managing impulsivity, striving for accuracy, gathering data through all senses, metacognition, thinking interdependently, thinking and communicating with clarity and precision, finding humor, persisting, applying past knowledge to new situations, questioning and posing problems, creating, listening with understanding and empathy, taking responsible risks, responding with wonderment and awe, remaining open to continuous learning".

Since this classification of habits of mind by Costa and Kallick (2009) was formulated with regard to primary school students, it only offers a view of general habits of mind. In addition, the cognitive and the affective dimension of these habits are not significantly differentiated from each other. This situation may cause difficulty in evaluating the habits of advanced students (e.g. PTs) and in measuring their beliefs about GHoM. For this reason, the cognitive and affective structure of the GHoM of PTs was revised by Bülbül (2016) (see Figure 2). For example, according to Costa and Kallick (2009) assessing the habit of "questioning and posing problems" together with the habit of "persisting" does not cause a problem in determining the habits of primary school students. However, when trying to determine the beliefs of a PT about their habits, it is necessary to consider the "questioning and posing problems" habits as belonging to the cognitive dimension. In this respect, Bülbül (2016) reviewed the literature and divided GHoM into cognitive and affective dimensions, as seen in Figure 2.

\subsection{Beliefs about Geometric Habits of Mind and Factors Affecting these}

Beliefs about geometric habits of mind are affective, as mentioned above (see in Figure 2). Since the affective dimension of GHoM is determined by the beliefs of the PTs, these are called beliefs about GHoM within the scope of the study. Beliefs about GHoM affect students' ability to solve a problem correctly. For example, if a student gives up trying when they cannot solve a geometry problem immediately, they are not focusing how to answer it successfully. However, if the student has the habits of "persisting" and "flexibility", which are on the affective dimension of GHoM, and the student is encouraged to try different solutions, they will be able to work out the correct answer. At this stage, it is important to determine the students' most effective habits of mind and support them in the learning environment. If the beliefs that directly affect success in geometry are determined, students can be guided in line with these beliefs. This study thus focused on the GHoM of PTs and the attempt was made to identify factors affecting these beliefs. In the study, the affective factors affecting GHoMs were classified as self-efficacy regarding geometry and attitude towards geometry (see in Figure 3).

Self-efficacy is an individual's self-judgement about their capacity to cope with the problems they encounter (Bandura, 1977; Elias \& MacDonald, 2007; Zimmerman, 1995). Self-efficacy 
regarding geometry is defined as an individual's ability to organize geometry problems, solve these problems successfully and to be confident in their capacity to do so (Kaba, Boğazliyan \& Daymaz, 2016). From this point of view, having high self-efficacy causes individuals to set more advanced goals for themselves and to be consistent in their decisions, and it also increases their success in problem-solving (Locke \& Latham, 1990). Beliefs about GHoM and problem-solving are intertwined (see in Figure 1) and both aim to overcome geometry problems students encounter.

There are many definitions of attitude in the literature; one of the most widely accepted is "an individual's pre-behavioral mental tendency with regard to the objects, events or situations around him and formed on the basis of previous life experiences". Similar to their beliefs in self-efficacy, individuals' positive or negative attitudes towards geometry affect their success in geometry lessons. The fact that there is a positive relationship between students' problem-solving success and attitudes (Chen \& Lin, 2019; Higgins, 1997) indicates why it is worthwhile to examine the relationship between the aforementioned concepts and beliefs about GHoM.

The factors which are thought to affect beliefs about GHoM are summarized in Figure 3. While self-efficacy regarding geometry and geometry attitude are among affective factors, PTs' success indicates their likely performance. The gender and their grade level are also determined to determine the PTs.

Figure 2

Cognitive and affective dimensions of GHoM

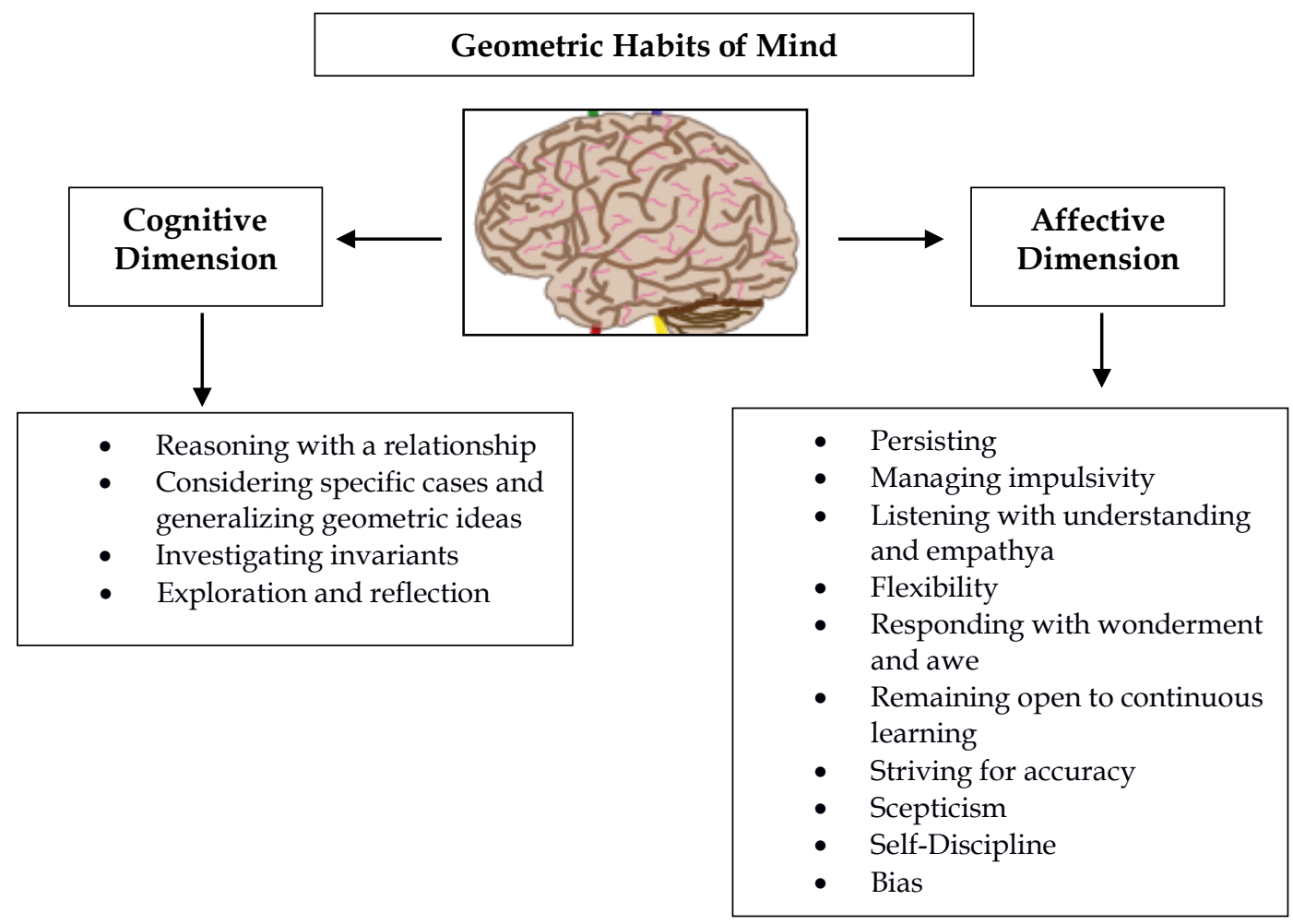

The cognitive dimension of GHoM has four aspects. These are the habits of "reasoning with a relationship", "considering specific cases and generalizing geometric ideas", "investigating invariants", and "exploration and reflection". This study focuses on the affective dimension of GHoM. As can be seen in Figure 1, the affective dimension of GHoM has ten indicators. The "persisting" component is related to keeping on trying and not giving up easily. The "managing impulsivity" component is about thinking before acting. The "listening with understanding" and "empathy" components are about listening to others attentively and with sensitivity. The "flexibility" component is about remaining open to alternatives or seeing other possibilities when a student makes a mistake while solving a problem. The "responding with wonderment and awe" component is about enjoying problem-solving and demonstrating curiosity. The "remaining open 
to continuous learning" component is related to striving for improvement; searching for new and better ways of doing things. "Striving for accuracy" is about using criteria to evaluate quality. "Skepticism" is related to checking the solution periodically, considering that there may be more than one solution to the problem. Finally, "self-discipline" and "bias" build one's belief in problem-solving and the ability to use geometric language effectively in this process.

Figure 3

Conceptual framework for examining the relationship between GHoM, affective factors and the gender of PTs

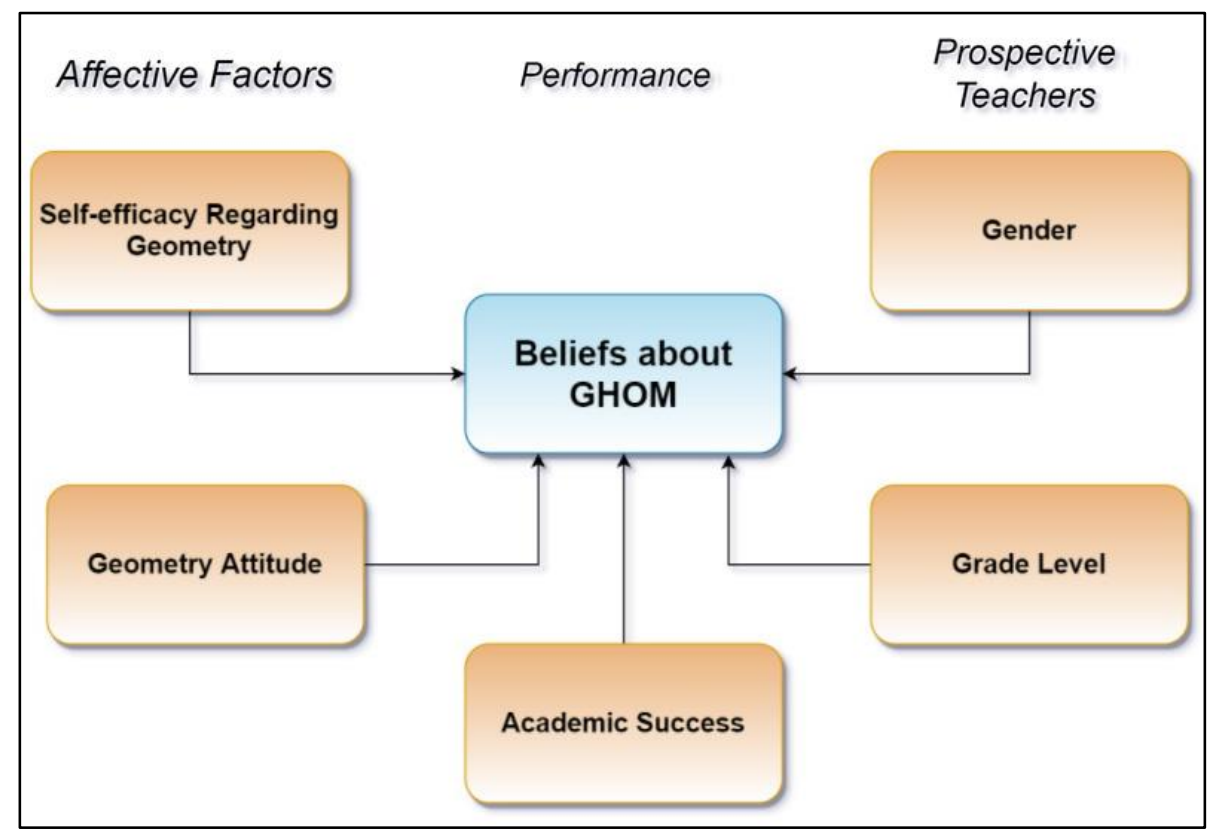

Studies have also demonstrated the effects of the affective factors mentioned above on students' success in geometry and problem-solving and how these are intertwined with GHoM. When the literature is examined, it can be seen that, in addition to affective factors, variables like gender, academic success and geometry success also have an influence on students' achievement (Eshel \& Kohavi, 2003). Students' success in geometry lessons and with geometry problems is related to the GHoM they have and their beliefs about GHoM (Driscoll et al., 2007; Driscoll et al., 2008; Lai \& Donsing, 2018). The thus question arises as to which affective factors affect beliefs about GHoM. Identifying PTs' beliefs about GHoM is very important as these beliefs will also affect their success in geometry. In this context, this study aimed to identify the factors affecting PTs' beliefs about GHoM. The effects of PTs' self-efficacy regarding geometry and their geometry attitude on their beliefs about GHoM were examined. The effects of PTs' gender, academic achievement, and their grade level of study on their beliefs about GHoM were also evaluated.

\section{Method}

A correlational research design was adopted into the study. This type of study is concerned with assessing relationships between two or more phenomena and usually involves a statistical measure of the degree of relationship, or correlation (McMillan \& Schumacher, 2001). Considering that this study was intended to examine the effects of PTs' self-efficacy regarding geometry and their attitude to geometry on their beliefs about GHoM, a correlational study design was believed to be appropriate.

\subsection{Participants}

The study was conducted with a total of 264 prospective mathematics teachers, 209 of whom were women and 55 men. It was thought that the different ways of teaching mathematics and geometry in universities in different regions of Turkey may have had different effects on the beliefs and 
attitudes of PTs regarding GHoM and geometry. For example, while courses such as 'Computeraided Geometry Teaching', 'Problem-Solving' and 'Geometric Thinking' are offered as elective courses in the western and inner regions of Turkey, some universities in the east do not offer these courses. Since these courses were also thought to be likely to affect the beliefs about GHoM, the study data were obtained from PTs studying at state universities in all regions of Turkey. In collecting the data, attention was paid to choose a similar number of PTs in each year of study. In this regard, data were obtained from 77 first-year, 75 second-year, 62 third year and 50 fourth-year PTs in the Mathematics Teaching Program.

\subsection{Instruments}

The study used the "Geometric Habits of Mind Belief Scale", "Self-Efficacy Scale for Geometry" and "Geometry Attitude Scale" as data collection tools over a period of one month. The grade point averages of the students in the mathematics and geometry-based courses (General Mathematics, Geometry, Computer-Aided Geometry Teaching, Problem-Solving, Modeling, Analytical Geometry I, Analytical Geometry II, Mathematics Education and Computer, Geometry and Measurement Teaching), which may have affected their GHoM, were obtained from their transcripts and considered to represent their level of academic achievement. The GHoM Belief Scale was developed by Bülbül (2016) by taking into consideration the affective dimension of the GHoM as shown in Figure 2. This scale, which Bülbül (2016) developed while preparing a learning environment for GHoM, consists of 22 items, seven of which are negative and 15 of which are positive. In this five-point Likert-type scale, there are five options for each item. These are "Strongly Disagree", "Disagree", "Partially, "Agree", and "Strongly Agree". The highest score obtainable from the items in the scale is 110 and the lowest is 22. Bülbül (2016), who conducted the validity and the reliability study of the scale, found the explained variance value to be $42.4 \%$ and the Cronbach Alpha reliability coefficient for the whole scale to be 0.88 . This indicated that the scale is highly reliable. The scale consists of a total of three dimensions which are "pre-preparation belief", "not giving up and perseverance", "belief in different solution strategies". The items in the scale include beliefs about GHoM such as "Before starting to solve a geometry problem, one should think about how to solve it"; "Even the most difficult geometry problems can be solved if one works hard"; "When trying to make a decision about a geometry problem, the results of each option should be compared to each other". The Self-Efficacy Scale for Geometry was developed by Cantürk-Günhan and Başer (2007). This scale consists of three dimensions: positive self-efficacy beliefs, use of geometry knowledge, negative self-efficacy beliefs. The scale, which has been found to be valid and reliable, consists of 25 items in total, 18 of which are positive, and seven of which are negative. The highest score obtainable from the scale is 125 and the lowest is 25. CantürkGünhan and Başer (2007) who conducted the validity and reliability study of the scale found the explained variance value as $42,42 \%$ and the Cronbach Alpha reliability coefficient as 0.87 . These values show that the scale is valid and reliable. The items in the scale include positive and negative self-efficacy towards geometry such as "I can easily understand the concepts in geometry", "I can use my geometry in other lessons", "I can write problems in geometry", "I don't think I am as good as my friends in geometry", "I don't have enough knowledge about geometry etc."

Another scale used in this study is the Geometry Attitude Scale, which was developed by Bindak (2004). This scale, which consists of 25 items in total, 16 of which are negative and nine of which are positive, is a five-point Likert-type scale. In other words, there are five options for each item to. These are "Strongly Disagree", “Disagree", "Partially Agree”, "Agree”, "Strongly Agree"”. The highest score obtainable from the scale is 125 and the lowest is 25. Bindak (2004) conducted the validity and reliability study of the scale and found the explained variance value to be $59.2 \%$ and the Cronbach Alpha reliability coefficient to be 0.94 . Items on the scale, which consists of four dimensions, include positive and negative attitudes towards geometry such as "trying to solve a geometry problem is fun", "no other lesson is as boring as Disagreeing a geometry lesson", "I would like to spend more time doing geometry", "I like geometry". 
The above-mentioned scales were applied to PTs by the researcher over a period of one month. Sufficient time was allocated to make sure PTs' views as represented by the scale were more objective.

\subsection{Data Analysis}

Before the analysis of the data obtained from PTs, the normality of the distribution of the data obtained from each scale was examined. For this, the Kolmogorov-Smirnov test was performed and the skewness and kurtosis values of the scores were examined.

In this study, according to the scores from the GHoM Belief Scale, the Self-efficacy Scale for Geometry, and the Geometry Attitude Scale, and the Kolmogorov-Smirnov test result of the data obtained from the academic achievements and gender scores of PTs, the significance value was between -1.5 and +1.5 . According to the literature, a significance value between -1.5 and +1.5 according to the Kolmogorov-Smirnov test indicates that the data are normally distributed (George \& Mallery, 2010; Tabachnick \& Fidell, 2013). Since the data obtained from the scales applied to PTs, the academic achievements of PTs and the gender variables showed normal distribution, parametric tests were performed on these data. In other words, the statistical method of multiple regression analysis was used when looking at the relationship between the prospective mathematics teachers' self-efficacy regarding geometry, their attitudes towards geometry, their academic achievements and their beliefs about GHoM. While the unrelated samples between PTs' grade level and their beliefs about GHoM were analyzed using one-way ANOVA, the relationship between the gender of PTs and their beliefs about GHoM were analyzed using the independent $\mathrm{t}$ test.

\section{Results}

This section of the study consists of three parts. The first part presents findings about how the affective factors and academic achievements of PTs affected their beliefs about GHoM. The second part presents the relationship between PTs' grade level and their beliefs about GHoM; the last part presents findings about the relationship between PTs' gender and their beliefs about GHoM presented.

\subsection{The Effect of PTs' Affective Factors on Their Beliefs about GHoM}

Multiple regression analysis was used to examine the relationship between the prospective mathematics teachers' self-efficacy regarding geometry, their attitude towards geometry, their academic achievements, and their beliefs about GHoM.

Table 1

Multiple Regression Analysis Results Regarding the Prediction of Beliefs of GHoM

\begin{tabular}{|c|c|c|c|c|c|c|c|}
\hline Variable & $B$ & $S E$ & $\beta$ & $T$ & $p$ & Binary $r$ & Partial $r$ \\
\hline Fixed & 12.091 & 4.632 & & 2.343 & .000 & - & - \\
\hline $\begin{array}{c}\text { Academic } \\
\text { Achievement }\end{array}$ & 0.082 & 0.052 & 0.068 & 1.097 & .001 & 0.623 & 0.442 \\
\hline Attitude & -0.031 & 0.050 & -0.201 & -0.383 & .068 & -0.412 & -0.092 \\
\hline Self-efficacy & 0.425 & 0.108 & 0.203 & 4.802 & .001 & 0.768 & 0.601 \\
\hline $\begin{array}{c}r=0.792 \\
F_{(3,26)}=13.80\end{array}$ & $\begin{array}{l}r^{2}=0 \\
p=.00\end{array}$ & & & & & & \\
\hline
\end{tabular}

The results of the regression analysis regarding the prediction of PTs about GHoM according to the variables of self-efficacy, attitude towards geometry and academic achievements are presented in Table 1. When the binary and partial correlations between the predictor variables and the dependent variable in Table 1 were examined, there was a positive and high level of correlation $(r=0.768)$ between PTs' self-efficacy regarding geometry and their beliefs about GHoM, but when the other variables are examined, it is seen that the correlation between these two variables was 
$r=0.601$. There was a positive high-level $(r=0.623)$ correlation between the academic achievements of the PTs and their beliefs about GHoM. When the other variables between this binary correlation were examined, the correlation decreased to $r=0.442$. Table 1 shows that there was a moderate-to-negative relationship $(r=-0.412)$ between the PTs' attitudes towards geometry and their beliefs about GHoM. When other variables were considered, it was observed that this relationship was negative, although to a low level(r=-0.092). As a result, it can be seen from Table 2 that there was a high-level and significant relationship between the PTs' attitudes, self-efficacy and academic achievement variables and their beliefs about GHoM $(r=0.792$, $\left.r^{2}=0.627, p<.01\right)$. These three variables explained about $62 \%$ of the total variance of PTs' beliefs about GHoM.

According to the standardized regression coefficient $(\beta)$, the order of the importance of predictor variables on beliefs about GHoM was self-efficacy, academic achievement and attitude. When the $t$ test results regarding the significance of the regression coefficients were examined, it can be seen in Table 1 that the variables of self-efficacy and academic achievement were a significant predictor of beliefs about GHoM. The relationship between PTs' beliefs about GHoM and their attitude, self-efficacy and academic achievement are presented graphically in Figure 4.

Figure 4

Relationship between PTs' beliefs about GHoM and self-efficacy, attitude and academic achievement

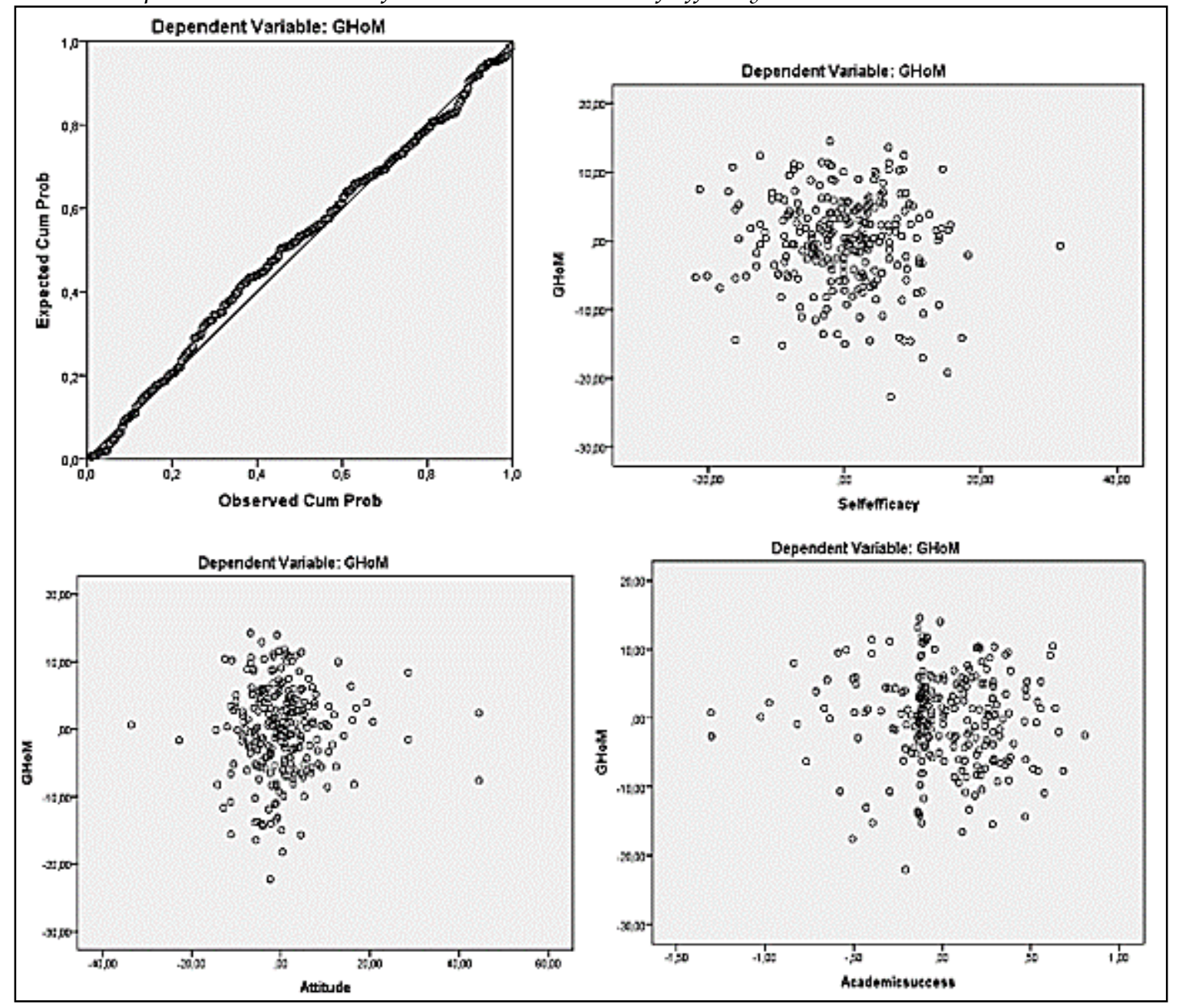

The graphs presented in Figure 4 indicate that the scatter diagram created for standardized residual values and standardized predicted values defined a linear relationship. In other words, according to the graphs, the relationship between PTs' academic achievements and their beliefs about GHoM showed normal distribution. This shows that there was a significant and high-level 
relationship between the academic achievements of the PTs and their beliefs about GHoM. Similarly, analyzing the scatter diagrams of the other variables, it can be said that the points tend to gather around an axis. Therefore, it can be argued that the diagrams show an approximate distribution to normal.

\subsection{Relationship between PTs' Grade Level and their Beliefs about GHoM}

Unrelated samples between the PTs' grade level and their beliefs about GHoM were analyzed using one-way ANOVA. Before the results of the analysis, the descriptive statistics of PTs' beliefs about GHoM are presented in Table 2.

Table 2

Descriptive Statistics of Beliefs about GHoM

\begin{tabular}{cccc}
\hline Grade & $N$ & $\bar{X}$ & $S D$ \\
\hline 1 & 77 & 79.31 & 6.43 \\
\hline 2 & 75 & 82.74 & 6.67 \\
\hline 3 & 62 & 83.22 & 5.46 \\
\hline 4 & 50 & 85.46 & 7.70 \\
\hline
\end{tabular}

According to the descriptive statistics presented in Table 2, most PTs were in the fourth $(\bar{X}=85.46)$ and third years of study $(\bar{X}=83.22)$. Additionally, while the average of the PTs studying in the second year was $\bar{X}=82.74$, the average of all the PTs was $\bar{X}=79.31$. Table 3 shows the results of the one-way ANOVA for the unrelated samples of the PTs, whose descriptive statistics are presented above.

Table 3

Results of one-way ANOVA relationship between grade level and beliefs about GHoM

\begin{tabular}{ccccccc}
\hline Source of Variance & $\begin{array}{c}\text { Sum of } \\
\text { Squares }\end{array}$ & SD & Mean Square & $F$ & $p$ & $\begin{array}{c}\text { Statistically } \\
\text { Significant Difference }\end{array}$ \\
\hline Between Groups & 305.998 & 4 & 76.499 & 12.072 & .000 & $3^{\text {rd }}$ year $>11^{\text {st }}$ year* \\
Within Groups & 4522.929 & 260 & 17.395 & & & $\begin{array}{l}4^{\text {th }} \text { year }>11^{\text {st }} \text { year*, } \\
2^{\text {nd }} \text { year }>11^{\text {st }} \text { year*, }\end{array}$
\end{tabular}

\begin{tabular}{lrrr} 
& Total & 4828.927 & 264 \\
\hline${ }^{*} \mathrm{p}<.01$ & &
\end{tabular}

As can be seen in Table 3, there was a significant difference between PTs' beliefs about GHoM and their grade level $(\mathrm{F}(4,260)=12.07, \mathrm{p}<.01)$. In other words, PTs' beliefs about GHoM varied significantly depending on their grade level. As a result of the analysis, it was determined that the variances were distributed homogeneously and, in this context, the Scheffe test and post-hoc analysis were conducted. According to the Scheffe test conducted to find out which groups differed by year of study, the beliefs of PTs in the third year, fourth year and second year of stud were more positive than the beliefs of those in the first year of study.

\subsection{Relationship between the Gender of PTs and their Beliefs about GHoM}

The relationship between the PTs' gender and their beliefs about GHoM were analyzed using the independent samples t-test. The results are as presented in Table 4.

Table 4

Results of t-test analysis of the relation between gender and beliefs about GHoM

\begin{tabular}{ccccccc}
\hline Gender & $N$ & $\bar{X}$ & $S D$ & $d f$ & $t$ & $p$ \\
\hline Female & 209 & 81.98 & 7.31 & 262 & \multirow{2}{*}{1.78} & \multirow{2}{*}{0.13} \\
Male & 55 & 81.33 & 6.27 & & \\
\hline
\end{tabular}


No significant difference was found between the PTs' beliefs about GHoM and their gender $\left(t_{(264)}=1.78 ; p=0.13>0.05\right)$. The female PTs' average beliefs about GHoM score was 7.31, while the male PTs' average problem-solving score was 6.27. This difference was statistically significant.

\section{Discussion and Conclusion}

This study identified factors affecting PTs' beliefs about GHoM. The factors affecting beliefs about GHoM were found to be both direct and indirect. While the direct factors consisted of affective factors and the academic achievements of the PTs, the indirect factors consisted the gender and grade level of the PTs. The definition of GHoM used here indicates that they are intertwined with problem-solving. Studies have shown that there is a positive significant relationship between beliefs about mathematical habits of mind in general, and GHoM in particular, and students' problem-solving achievement (Bülbül \& Güler, 2021; Driscoll et al., 2007; Driscoll et al., 2008; Gordon, 2011; Jacobbe \& Millman, 2009; Lai \& Donsing, 2018; Matsuura et al., 2013). This means that a relationship can be found between students' beliefs about GHoM and beliefs about problemsolving.

In the study, a positive and high-level relationship was found between PTs' self-efficacy of geometry and their beliefs about GHoM. Self-efficacy in the context of geometry is the individuals' confidence in themselves to be able to organize and successfully solve geometry problems (Erdoğan, Baloğlu \& Kesici, 2011; Deringöl, 2020). "Not giving up and perseverance", which is a dimension of the GHoM Beliefs scale, coincides with the belief in self-efficacy regarding geometry. This study found that the stronger the PTs' self-efficacy regards geometry, the stronger their beliefs about GHoM. Similarly, Wimmer et al. (2020) showed that negative self-concept was related to sustained decrease in motivation and academic achievement. Similarly, the researchers stated in the literature that students' perceptions of self-efficacy in problem-solving positively affect their beliefs and problem-solving achievement (Güven \& Cabakcor, 2012; Hoffman, 2010; Kloosterman \& Stage, 1992; Li, Song et al., 2020; Li, Gow et al., 2020; Pajares \& Kranzler, 1995; Pajares \& Miller, 1994; Pimta, Tayruakham \& Nuangchalerm, 2009; Russo, Bobis, Downton, Hughes, Livy, McCormick \& Sullivan, 2020). Another result obtained from the study was that there was a moderate-to-negative relationship between the PTs' attitudes towards geometry and their beliefs about GHoM. In other words, when the PTs' positive attitudes towards geometry increased, their beliefs about GHoM decreased. A similar result was obtained in the study conducted by Erşen (2017) examining the relationship between students' GHoM and their attitudes towards geometry. Erşen (2017) found a moderate relationship between students' attitudes and GHoM. Examining the reason for the presence of a moderate, negative relationship, it was observed that the routine nature of some geometry courses at universities may lead to some a lack of interest in PTs. In other words, conducting some geometry classes with paper and pencil only may give rise to a negative attitude towards geometry in general. Using dynamic software may enable PTs to develop a more positive attitude towards geometry can make geometry lessons more fun and ensure that concepts are permanently learned (Clements, 2003).

A positive, high-level relationship was found between the academic achievement of the PTs and their beliefs about GHoM. The relevant literature shows that GHoM and beliefs about these habits have a positive effect on students' achievements (Cuoco, Goldenberg \& Mark, 1996; Dostal, 2000; Guenther, 1997; Hu, 2005; Marshall 2004). Additionally, as Jacobbe and Millman (2009) indicated, the fact that students' habits of mind are intertwined with problem-solving supports the result that their belief in their capacity to solve problems affects their academic achievement positively (Hanson \& Lucas, 2020). In other words, as PTs' beliefs about GHoM become more positive, so their academic performance will also improve.

Another result obtained from the study was that there was a relationship between the PTs' grade level and their beliefs about GHoM. It was found that the beliefs about GHoM that the PTs had in the fourth, third and second years, were, respectively, more positive than the beliefs they had in the first year. This may be due to PTs' gaining an understanding of the content of geometry 
courses while at university and changing their beliefs and attitudes as a result. In other words, during the teaching process, the PTs had encountered a large number of geometry problems that they had to find ways to solve. Driscoll et al. (2007) stated that an increase in the number of geometry problems that students were asked to solve improved their GHoM and their beliefs about these habits. This explains why the beliefs of the PTs who were more advanced in their studies were more positive in the current study. PTs in the first year of study may have difficulty in properly formulating beliefs about GHoM because they do not have a full knowledge of the geometry courses within the university curricula. In addition, beliefs may not be brought to an individuals' conscious awareness until they are fully internalized. However, as the grade level progressed, the average scores for the PTs' beliefs about GHoM showed that they had more positive views of these habits. Costa and Kallick's (2009) statement, which suggests that students' behaviors become more habitual as they get older, supports the result obtained in the study. In the study, no significant relationship was found between the gender of the PTs and their beliefs about GHoM. In the literature, different results have been found in studies where habits of mind, beliefs and successful problem-solving have been examined in the context of gender. In recent years, some studies have stated that the gender variable does not affect beliefs and success in problemsolving or academic achievement, while some studies have stated it does (Alghadari, Herman \& Prabawanto, 2020; Gall, Borg \& Gall, 1996; Martin, Mansour \& Malmberg, 2020; Ramírez-Uclés \& Ramírez-Uclés, 2020).

\section{References}

Alghadari, F., Herman, T., \& Prabawanto, S. (2020). Factors affecting senior high school students to solve three-dimensional geometry problems. International Electronic Journal of Mathematics Education, 15(3), em0590. http:// doi.org/10.29333/iejme/8234

Bandura, A. (1997). Self-efficacy: The exercise of control. W. H. Freeman and Company.

Bindak, R. (2004). Study of reliability and validity with and application for geometry attitude scale (Unpublished doctoral dissertation). Dicle University, Diyarbakır, Turkey.

Bülbül, B. Ö. (2016). The evaluation of the learning environment designed for improve the geometric habits of mind of mathematics pre-service teachers. (Unpublished doctoral dissertation). Karadeniz Technical University, Trabzon, Turkey.

Bülbül, B. Ö., \& Güler, M. (2021). Can geometry achievement and geometric habits of mind be improved online? Reflections from a computer-aided intervention. Journal of Educational Technology Systems, 49(3), 376-398. https://doi.org/10.1177/0047239520965234

Bülbül, B. Ö., \& Güven, B. (2020). The change of geometric thinking habit of prospective teachers. Pamukkale University Journal of Education, 48, 431-453. http:// doi.org/10.9779/pauefd.513220

Bülbül, B. Ö., \& Güven. B. (2019). Examining the relationship between geometric habits of mind and the mathematics achievement: The case of mathematics preservice teachers. Turkish Journal of Computer and Mathematics Education, 10(3), 711-731. http://doi.org/10.16949/turkbilmat.495105

Cantürk-Günhan, B., \& Başer, N. (2007). The development of self-efficacy scale toward geometry. Hacettepe University Journal of Educations, 33, 68-76.

Chen, S.Y., \& Lin, S.W. (2019). A Cross-cultural study of mathematical achievement: From the perspectives of one's motivation and problem-solving style. International Journal of Science and Mathematics Education, 18, 1149-1167. http:// doi.org/10.1007/s10763-019-10011-6

Clements, D. (2003). Teaching and learning geometry. Research Companion to Principles and Standards for School Mathematics. Reston, VA: NCTM.

Costa, A. L., \& Kallick, B. (2009). Habits of mind across the curriculum: Practical and creative strategies for teachers. Alexandria, VA: Association for Supervision and Curriculum Development.

Cuoco, A., Goldenberg, E. P., \& Mark, J. (1996). Habits of mind: An organizing principle for mathematics curricula. The Journal of Mathematical Behavior, 15(4), 375-402. http://doi.org/10.1016/S07323123(96)90023-1 
Deringöl, Y. (2020). Middle school students' perceptions of their self-efficacy in visual mathematics and geometry: a study of sixth to eighth grade pupils in Istanbul province, Turkey. Education 3-13. International Journal of Primary, Elementary and Early Years Education, 48(8), 1012-1023. http:// doi.org/10.1080/03004279.2019.1709527

Đokić, O. J. (2018). Research perspectives of initial geometry education. Journal of Pedagogical Research, 2(2), $102-111$.

Dostal, P. (2000). An examination of explanatory style and habits of the mind as correlates of academic achievement in 7th-grade gifted students (Unpublished master's thesis). California State University, Long Beach, USA.

Driscoll, M. J., DiMatteo, R. W., Nikula, J., \& Egan, M. (2007). Fostering geometric thinking: A guide for teachers grades 5-10. Portsmouth, NH: Heinemann.

Driscoll, M. J., DiMatteo, R. W., Nikula, J., Egan, M., Mark, J., \& Kelemanik, G. (2008). The fostering geometric thinking toolkit: A guide for staff development. Heinemann.

Elias, S. M., \& MacDonald, S. (2007). Using past performance, proxy efficacy, and academic self-efficacy to predict college performance. Journal of Applied Social Psychology, 37, 2518-2531. http://doi.org/10.1111/j.1559-1816.2007.00268.x

Erdoğan, A., Baloğlu, M., \& Kesici, Ş. (2011). Gender differences in geometry and mathematics achievement and self-efficacy beliefs in geometry. Eurasian Journal of Educational Research, 43, 91-106.

Erşen, Z. B. (2017). Investigation of the relationship between 10th science high school students' geometric habits of mind and attitudes towards geometry. SDU International Journal of Educational Studies, 4(2), 7185.

Erşen, Z. B., Ezentaş, R., \& Altun, M. (2018). Evaluation of the teaching environment for improve the geometric habits of mind of tenth grade students. European Journal of Education Studies. 4(6), 47-65. http:// doi.org/10.5281/zenodo.1239849

Eshel, Y., \& Kohavi, R. (2003). Perceived classroom control, self-regulated learning strategies, and academic achievement. Educational Psychology, 23(3), 249-260. http://doi.org/10.1080/0144341032000060093

Gall, M. D., Borg, W. R., \& Gall, J. P. (1996). Educational research: An introduction. White Plains NY: Longman Publishers.

George, D., \& Mallery, M. (2010). Spss for windows step by step: A simple guide and reference 17.0 update. Allyn \& Bacon, Inc.

Goldenberg, E. P. (1996). "Habits of Mind" as an organizer for the curriculum. Journal of Education, 178(1), 13-34. http:/ / doi.org/10.1177/002205749617800102

Gonzalez, G., \& Herbst, P. G. (2006). Competing arguments for the geometry course: Why were American high school students supposed to study geometry in the twentieth century? International Journal for the History of Mathematics Education, 1(1), 7-33.

Gordon, M. (2011). Mathematical habits of mind: Promoting students' thoughtful considerations. Journal of Curriculum Studies, 43(4), 457-469. http:/ / doi.org/10.1080/00220272.2011.578664

Guenther. J, S. (1997). An examination of fifth grade students' consideration of habits of mind: A case study (Unpublished doctoral dissertation). University of Missouri, Columbia, USA.

Güven, B., \& Çabakçor, B.Ö. (2012). Factors influencing mathematical problem-solving achievement of seventh grade Turkish students. Learning and Individual Differences. 23, 131-137. http:// doi.org/10.1016/j.lindif.2012.10.003

Hanson, J., \& Lucas, B. (2020). The case for technology habits of mind. In P. J. Williams, \& D. Barlex (Eds.), Pedagogy for technology education in secondary schools (pp. 45-64). Springer.

Herbst, P. (2006). Teaching geometry with problems: Negotiating instructional situations and mathematical tasks. Journal for Research in Mathematics Education, 37, 313-347.

Higgins, K. M. (1997). The effect of year-long instruction in mathematical problem solving on middle-school student's attitudes, beliefs and abilities. Journal of Experimental Education, 66(1), 5-28. http:// doi.org/10.1080/00220979709601392

Hoffman, B. (2010). I think I can, but I'm afraid to try: The role of self-efficacy beliefs and mathematics anxiety in mathematics problem-solving efficiency. Journal of Learning and Individual Differences, 20, 276283. http:// doi.org/10.1016/j.lindif.2010.02.001

$\mathrm{Hu}, \mathrm{H}-\mathrm{W}$. (2005). Developing siblings and peer tutors to assist native Taiwanese children in learning habits of mind for math success (Unpublished master's thesis). University of Massachusetts Amherst, USA.

Jacobbe, T., \& Millman, R. S. (2009). Mathematical habits of the mind for preservice teachers. School Science and Mathematics, 109(5), 298-302. http://doi.org/10.1111/j.1949-8594.2009.tb18094.x 
Kloosterman, P., \& Stage, F. K. (1992). Measuring beliefs about mathematical problem solving. School Science and Mathematics, 92, 109-115. http://doi.org/10.1111/j.1949-8594.1992.tb12154.x

Lai, Y., \& Donsing, A. (2018). Using geometric habits of mind to connect geometry from a transformation perspective to graph transformations and abstract algebra. In N. H. Wasserman (Ed), Connecting abstract algebra to secondary mathematics, for secondary mathematics teachers (pp. 263-290). Springer.

Li, L., Gow, A. D. I., \& Zhou, J. (2020). The role of positive emotions in education: A neuroscience perspective. Mind, Brain and Education, 14(3), 220-234. http://doi.org/10.1111/mbe.12244

Li, X., Song, N., Hwang, S., \& Cai, J. (2020). Learning to teach mathematics through problem posing teachers' beliefs and performance on problem posing. Educational Studies in Mathematics, 105, 325-347. http:// doi.org/10.1007/s10649-020-09981-0

Lim, K. H., \& Selden, A. (2009). Mathematical habits of mind. In S. L. Swars, D. W. Stinson, \& S. LemonsSmith (Eds.), Proceedings of the 31st annual meeting of the North American Chapter of the International Group for the Psychology of Mathematics Education (pp. 1576-1583). Georgia State University.

Locke, E. A., \& Latham, G. P. (1990). A theory of goal setting and task performance. Englewood Cliffs, NJ: Prentice Hall.

Marshall, A. R. (2004). High school mathematics habits of mind instruction: student growth and development (Unpublished master's thesis). Southwest Minnesota State University, USA.

Martin, A.J., Mansour, M., \& Malmberg, L.E. (2020). What factors influence students' real-time motivation and engagement? An experience sampling study of high school students using mobile technology. Educational Psychology, 40(9), 1113-1135. https://doi.org/10.1080/01443410.2018.1545997

Matsuura, R., Sword, S., Piecham, M. B., Stevens, G., \& Cuoco, A. (2013). Mathematical habits of mind for teaching: Using language in algebra classrooms. The Mathematics Enthusiast, 10(3), 735-776.

McMillan, J. H., \& Schumacher, S. (2001). Research in education: A conceptual introduction (Fifth Edition). Addison Wesley Longman.

National Council of Teachers of Mathematics. (2000). Principles and standards for school mathematics. NCTM.

Pajares, F., \& Kranzler, J. (1995). Self-efficacy beliefs and general mental ability in mathematical problemsolving. Contemporary Educational Psychology, 20(4), 426-443. http://doi.org/10.1006/ceps.1995.1029

Pajares, F., \& Miller, M. D. (1994). The role of self-efficacy and self-concept beliefs in mathematical problemsolving: A path analysis. Journal of Educational Psychology, 86, 193-203. http://doi.org/10.1037/00220663.86.2.193

Pimta, S., Tayruakham, S., \& Nuangchalerm, P. (2009). Factors influencing mathematic problem-solving ability of sixth grade students. Journal of Social Sciences, 5(4), 381-385. http:// doi.org/10.3844/jssp.2009.381.385

Ramírez-Uclés, I.M., \& Ramírez-Uclés, R. (2020). Gender differences in visuospatial abilities and complex mathematical problem solving. Frontiers in Psychology, 11, 191. http://doi.org/10.3389/fpsyg.2020.00191

Russo, J., Bobis, J., Downton, A., Hughes, S., Livy, S., McCormick, M., \& Sullivan, P. (2020). Elementary teacher's beliefs on the role of struggle in the mathematics classroom. Journal of Mathematical Behavior, 58, 1-11. http:// doi.org/10.1016/j.jmathb.2020.100774

Schoenfeld, A. H. (1992). Learning to think mathematically: Problem solving, metacognition, and sensemaking in mathematics. In D. Grouws (Ed.), Handbook of research on mathematics teaching and learning (pp. 334-370). New York: Macmillan.

Wimmer, S., Paechter, M., Lackner, H.K., Papousek, I. (2019). Effects of self-concept on restoring a positive motivational state after an exam-like situation. Mind, Brain and Education, 14(1), 5-15. http://doi.org/10.1111/mbe.12222

Yavuzsoy-Köse, N., \& Tanışl1, D. (2014). Primary school teacher candidates' geometric habits of mind. Educational Sciences: Theory and Practice, 14(3), 1220-1230. http://doi.org/10.12738/estp.2014.3.1864

Zimmerman, B. J. (1995). Self-regulation involves more than metacognition: A social cognitive perspective. Educational Psychologist, 30(4), 217-221. http://doi.org/10.1207/s15326985ep3004_8 